\title{
PERSYARIKATAN MUHAMMADIYAH MERESPON TANTANGAN DUNIA KERJA DAN KOMPETISI GLOBAL ${ }^{1}$
}

\author{
Achmad Zulfikar \\ Pemuda Muhammadiyah Kota Makassar \\ Email: apa@kabarfikar.com
}

\begin{abstract}
Andi Azhar
Pimpinan Cabang Istimewa Muhammadiyah (Taiwan) Republic of China

Email: me@andiazhar.com
\end{abstract}

\begin{abstract}
ABSTRAK
Muhammadiyah telah meletakkan pilar kemandirian ekonomi sebagai ciri Persyarikatan dan ijtihad ini terus berlanjut dengan mengelola amal usaha dan mendirikan unit usaha. Upaya ini juga ditopang keterlibatan Muhammadiyah yang juga ambil bagian di tengah masyarakat global. Tujuan penulisan makalah ini untuk mengungkap bagaimana Persyarikatan Muhammadiyah merespon tantangan dunia kerja dan kompetisi global. Tulisan ini menggunakan metode kualitatif dengan pengumpulan data melalui kajian literatur dan analisis data menggunakan metode induktif. Setelah mempertimbangkan hal-hal yang dibutuhkan oleh Indonesia berdasarkan kondisi ketenagakerjaan Indonesia dan posisi Indonesia dalam Global Competitive Index (GCI). Tulisan ini memberikan dua tawaran konkrit bagi Persyarikatan Muhammadiyah dalam merespon tantangan dunia kerja dan kompetisi global. Pertama, menerapkan pendekatan pembelajaran interdisiplin Science, Technology, Engineering and Mathematics (STEM) melalui sekolah-sekolah dan perguruan tinggi Muhammadiyah agar tercipta kader dan lulusan yang mampu bersaing di era globalisasi. Kedua, pemberdayaan masyarakat yang dilakukan Muhammadiyah berorientasi terhadap Revolusi Industri 4.0 sehingga luaran dari revolusi ini akan mendatangkan keuntungan dan kesejahteraan bagi warga Persyarikatan Muhammadiyah serta rakyat Indonesia secara luas.
\end{abstract}

Kata Kunci: Persyarikatan Muhammadiyah, Dunia Kerja, Kompetisi Global, Pendekatan STEM

\begin{abstract}
Muhammadiyah has put the pillar of economic independence as a hallmark of the organization and this effort continues with managing the business charity and establishing a business unit. This effort is also supported by the involvement of Muhammadiyah which also took part in the global community. The purpose of this paper is to reveal how Persyarikatan Muhammadiyah respond to the challenges of the employment world and global competition. This paper uses qualitative methods with data collection through literature review and data analysis using inductive methods.

\footnotetext{
1 Artikel yang diikutsertakan dalam Call for Paper "Kolokium Pemikiran Kaum Muda Muhammadiyah" yang diselenggarakan oleh Lembaga Pengkajian dan Pengamalan Islam (LPPI) Universitas Muhammadiyah Yogyakarta (UMY), Ikatan Mahasiswa Muhammadiyah Komisariat UMY dan Jaringan Intelektual Muda Muhammadiyah (JIMM) pada Kamis-Jum’at, 12-13 April 2018 di Kampus Terpadu UMY.
} 
After considering the Indonesia needs based on Indonesia's employment conditions and Indonesia's position in the Global Competitive Index (GCI). This paper provides two concrete offers for the Persyarikatan Muhammadiyah to respond the challenges of the employment world and global competition. First, applying interdisciplinary learning through Science, Technology, Engineering and Mathematics (STEM) approach in Muhammadiyah schools and universities to create cadres and graduates who can compete in the globalization era. Second, community service by Muhammadiyah's should be oriented towards Industrial Revolution 4.0, so that the output of this revolution will bring benefits and prosperity for the Persyarikatan Muhammadiyah society and Indonesian people widely.

Keywords: Persyarikatan Muhammadiyah, Employment World, Global Competition, STEM Approach

\section{PENDAHULUAN}

Awal berdirinya persyarikatan Muhammadiyah tidak terlepas dari peran kalangan ekonomi maju, yaitu para produsen dan pedagang di Nusantara. Bahkan para ulama Muhammadiyah juga kebanyakan berlatarbelakang pengusaha dan pedagang. Memperhatikan kondisi ekonomi para perintis Muhammadiyah maka dapat dikatakan para perintis pendukung Persyarikatan memiliki kemandirian ekonomi. Mereka dapat memobilisasi dana besar, karena mereka sendiri memiliki dana tersebut. Mereka dapat membiayai kegiatan persyarikatan melalui wakaf, zakat dan sedekah, sehingga Persyarikatan dapat bergerak dengan cepat di berbagai daerah. (Sutan, 2012:6)

Keadaan Muhammadiyah di awal berdirinya patut direfleksikan dengan kondisi kekinian Persyarikatan. Saat ini Muhammadiyah telah semakin berkembang dan ijtihad dalam mendorong kemandirian ekonomi terus berlanjut dengan mengelola amal usaha dan mendirikan unit-unit usaha. Hal ini sejalan dengan poin keenam dalam usaha Muhammadiyah yakni memajukan perekonomian dan kewirausahaan ke arah perbaikan hidup yang berkualitas. Di samping itu, Muhammadiyah di tengah masyarakat global juga perlu mengambil bagian. Hal ini juga sejalan dengan poin kesembilan dalam usaha Muhammadiyah yakni mengembangkan komunikasi, ukhuwah, dan kerjasama dalam berbagai bidang dan kalangan masyarakat dalam dan luar negeri.

Persyarikatan Muhammadiyah dengan ijtihad dan amal usaha yang dimiliki tentu menjadi kekuatan yang diperhitungkan dalam kancah nasional dan internasional. Sehingga Muhammadiyah harus terus bergerak maju dengan menawarkan gagasan konkrit dan strategis untuk memberdayakan sumber daya manusia (SDM) Muhammadiyah dalam menyokong Indonesia berkemajuan. Penulis ingin mengungkap bagaimana Persyarikatan Muhammadiyah merespon tantangan dunia kerja dan kompetisi global.

\section{METODOLOGI}

Tulisan ini menggunakan metode kualitatif dengan pengumpulan data melalui kajian literatur yang bersumber dari jurnal dan dokumen yang dapat diakses secara online mengenai hal-hal terkait upaya Persyarikatan Muhammadiyah merespon 
tantangan dunia kerja dan kompetisi global. Teknik analisis data menggunakan metode induktif, yakni metode yang menggunakan alur berpikir dengan penarikan kesimpulan berdasarkan data-data yang bersifat khusus. Penulis menggunakan metode ini untuk menyimpulkan kajian literatur yang dikumpulkan, kemudian dikategorikan, dielemininasi dan dilakukan penarikan kesimpulan.

\section{HASIL DAN PEMBAHASAN \\ Kondisi Ketenagakerjaan Indonesia}

Indonesia merupakan kepulauan terbesar di dunia dengan jumlah penduduk 237,6 juta dari hasil Sensus Penduduk 2010 yang terdiri dari 119,5 juta laki-laki dan 118 juta perempuan. Indonesia menempati peringkat keempat dari sepuluh negara yang mencatat peningkatan Human Development Index (HDI) pada tahun 2010. Dari 135 negara di seluruh dunia yang dihitung berdasarkan tingkat pendidikan, kesehatan dan pendapatan per kapita, peringkat Indonesia naik dari posisi 111 ke 108. Meskipun dari sisi kualitas hidup manusia Indonesia menggembirakan, kondisi ini sesungguhnya juga memperlihatkan munculnya tantangan lain, yakni persoalan ketenagakerjaan. Dengan usia hidup yang panjang dan pendidikan yang semakin tinggi memunculkan tantangan pemenuhan pasar tenaga kerja. Terjadi ketidakseimbangan pertumbuhan, yakni antara tenaga kerja dan lapangan kerja. (Kementerian Tenaga Kerja dan Transmigrasi, 2011:9)

Pertumbuhan penduduk tidak selalu berbanding lurus dengan penyediaan lapangan kerja, karena lapangan kerja akan mengikuti jumlah angkatan kerja yang bertambah dengan lebih cepat daripada penduduk. Hal ini dikarenakan bersamaan dengan pertumbuhan penduduk, tenaga kerja (penduduk berusia 15 tahun ke atas) dan angkatan kerja juga terus bertambah. Tenaga kerja bertambah dari 79,5 juta orang pada 1971 menjadi 88,3 juta orang pada 1980 dan 155,5 juta orang pada 2005. Pada 2009, tenaga kerja diperhitungkan menjadi 168,9 juta orang. (Kementerian Tenaga Kerja dan Transmigrasi, 2011:25-26; Zulfikar, 2015)

Tabel 1. Jumlah Penduduk dan Angkatan Kerja Indonesia 1971-2009

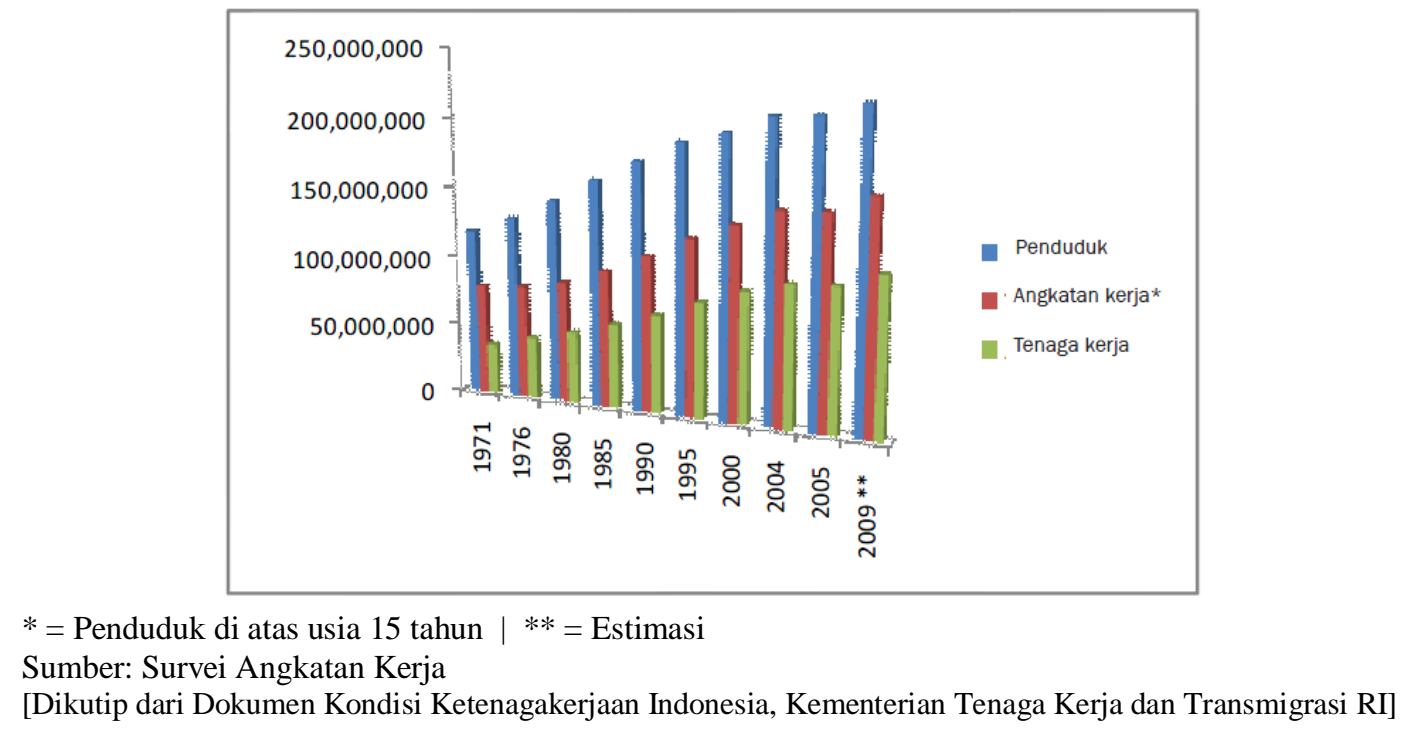


Hal yang patut disyukuri yakni kondisi ketenagakerjaan di Indonesia menunjukkan adanya perbaikan, kondisi ini digambarkan dengan adanya peningkatan kelompok penduduk yang bekerja, serta menurunnya angka pengangguran. Pada 2010 jumlah angkatan kerja mencapai 116 juta orang atau naik 2,26 juta orang dibandingkan tahun sebelumnya. Sedangkan penduduk yang bekerja juga terjadi peningkatan, pada 2010 mencapai 107,41 juta orang naik dari 2009 sebesar 2,92 juta orang. (Kementerian Tenaga Kerja dan Transmigrasi, 2011:26; Zulfikar, 2015)

Akibat dari pertambahan angkatan kerja yang tidak dapat diikuti dengan pertambahan perluasan kesempatan kerja menyebabkan jumlah pengangguran terbuka terus bertambah, sementara itu jumlah setengah pengangguran tetap tinggi. Tingkat pengangguran meningkat dari 1,7 persen pada 1980 menjadi 6,08 persen dalam tahun 2000 dan menjadi 10,3 persen pada 2005. Tingkat pengangguran terbuka (TPT) di Indonesia pada 2010 mencapai 7,41 persen, ini mengalami penurunan dibanding 2009 yang sebesar 8,14 persen. (Kementerian Tenaga Kerja dan Transmigrasi, 2011:26; Zulfikar, 2015)

Tabel 2. Tingkat Pengangguran Berdasarkan Tingkat Pendidikan

\begin{tabular}{|lrrrrr|}
\hline Tingkat Pendidikan & \multicolumn{2}{c}{$\mathbf{2 0 0 8}$} & \multicolumn{2}{c|}{$\mathbf{2 0 0 9}$} & $\mathbf{2 0 1 0}$ \\
\hline & Februari & Agustus & Februari & Agustus & Februari \\
\hline 1. SD ke bawah & 4,7 & 4,57 & 4,51 & 3,78 & 3,71 \\
\hline 2. Sekolah Menengah Pertama & 10,05 & 9,39 & 9,38 & 8,37 & 7,55 \\
\hline 3. Sekolah Menengah Atas & 13,69 & 14,31 & 12,36 & 14,5 & 11,9 \\
\hline 4. Sekolah Menengah Kejuruan & 14,8 & 17,26 & 15,69 & 14,59 & 13,81 \\
\hline 5. Diploma I/II/III & 16,35 & 11,21 & 15,38 & 13,66 & 15,71 \\
\hline 6. Universitas & 14,25 & 12,59 & 12,94 & 13,08 & 14,24 \\
\hline JUMLAH & 8,46 & 8,39 & 8,14 & 7,87 & 7,41 \\
\hline
\end{tabular}

Sumber: Data BPS, Sensus Penduduk 2010

Pengangguran terbuka pada umumnya merupakan fenomena daerah perkotaan, kebanyakan di kalangan usia muda, terutama lulusan serta putus sekolah tingkat dasar dan menengah. Tingkat pengangguran pada 2005 tercatat 10,26 persen, akan tetapi di kalangan kelompok umur 15-19 tahun dan 20-24 tahun mencapai 34,88 persen dan 25,24 persen. Pengangguran di daerah perkotaan hampir dua kali dari tingkat pengangguran di wilayah pedesaan. Tingkat pengangguran di pedesaan 7,98 persen, sementara di daerah perkotaan mencapai 13,51 persen. (Kementerian Tenaga Kerja dan Transmigrasi, 2011:27; Zulfikar, 2015)

Lapangan kerja bagi kaum muda (usia 15-24 tahun) memang terasa terkena dampak krisis keuangan Asia yang terjadi sebelum akhir 1990-an. Jumlah lapangan kerja bagi kaum muda pada 2009 masih berada di bawah tingkat yang tercatat pada 1991 sehingga menyebabkan banyaknya pengangguran di kalangan muda. Tantangan yang dihadapi kaum muda untuk mendapatkan pekerjaan di Indonesia ditandai dengan tingginya angka pengangguran di kalangan muda sebesar 22,2 persen di tahun 2009, 
yang secara signifi kan lebih tinggi dibandingkan rata-rata kawasan (13,9 persen untuk Asia Tenggara dan Pasifik) dan rata-rata dunia (12,8 persen). (Kementerian Tenaga Kerja dan Transmigrasi, 2011:27; Zulfikar, 2015)

Data di atas menunjukkan bahwa Indonesia mengalami persoalan dalam penyediaan lapangan kerja. Walaupun belum menggambarkan kondisi aktual dalam kurun waktu 2010-2017, tetapi dari tren yang terlihat pertumbuhan penduduk sejak 1971 tidak sebanding dengan jumlah angkatan kerja dan tenaga kerja yang terserap. Sehingga dibutuhkan terobosan tidak hanya dari pemerintah, melainkan juga Persyarikatan Muhammadiyah sebagai organisasi masyarakat Islam dan juga bagian dari gerakan masyarakat sipil (civil society) yang mampu menyediakan tawaran-tawaran dalam merespon tantangan dunia kerja.

\section{Posisi Indonesia dalam Global Competitiveness Index}

Mengukur kompetisi Indonesia di kancah internasional dapat ditinjau dari berbagai sisi, salah satunya dari daya saing (competitiveness). Young (n.d.) mendefinisikan competitiveness as the degree to which a nation can, under free and fair market conditions, produce goods and services that meet the test of international markets while at the same time maintaining or expanding the real incomes of its citizens. (Daya saing adalah ukuran suatu negara dapat berada dalam keadaan pasar bebas dan adil, menghasilkan barang dan jasa yang memenuhi standar pasar/kebutuhan internasional di saat yang sama mengelola dan mengembangkan pendapatan yang riil dari warga negaranya).

Sedangkan World Economic Forum (WEC) mendefinisikan competitiveness as the set of institutions, policies, and factors that determine the level of productivity of an economy, which in turn sets the level of prosperity that the economy can achieve. Daya saing adalah seperangkat institusi, kebijakan, dan faktor-faktor yang menentukan tingkatan produktivitas ekonomi yang dipersiapkan untuk peningkatan kesejahteraan yang dapat dicapai oleh ekonomi tersebut. WEC juga merupakan lembaga yang melakukan pemeringkatan global bernama Global Competitiveness Index (GCI). Lembaga ini telah merilis hasil GCI Tahun 2017-2018 yang menempatkan Indonesia pada urutan 36 dari 137 negara, setelah pada tahun 2016-2017 pada peringkat 41 dari 138 negara. (World Economic Forum, 2017a:11)

Indeks global (GCI) ini mengkombinasikan 114 indikator yang terkait produktivitas dan pencapaian kesejahteraan jangka panjang. Indikator ini dikelompokkan ke dalam 12 pilar yakni: kelembagaan (institutions), infrastruktur, ekonomi makro, lingkungan, kesehatan dan pendidikan dasar, pendidikan tinggi, pendidikan dan pelatihan, efisiensi pasar jasa (goods market efficiency), efisiensi pasar tenaga kerja (labor market efficiency), pengembangan pasar keuangan (financial market development), kesiapan teknologi, ukuran pasar, (market size), kecanggihan berbisnis dan inovasi (business sophistication, and innovation). Keduabelas pilar ini dikelompokkan lagi ke dalam tiga sub-indeks yakni prasyarat dasar (basic requirements), peningkatan efisiensi (efficiency enhancers), dan inovasi dan faktor- 
faktor inovasi dan kecanggihan (innovation and sophistication factors). (World Economic Forum, 2017a:11) Posisi Indonesia terhadap keduabelas pilar tersebut berdasarkan hasil GCI Tahun 2017-2018 ditampilkan sebagai berikut:

Gambar 1. Posisi Indonesia dalam GCI 2017-2018

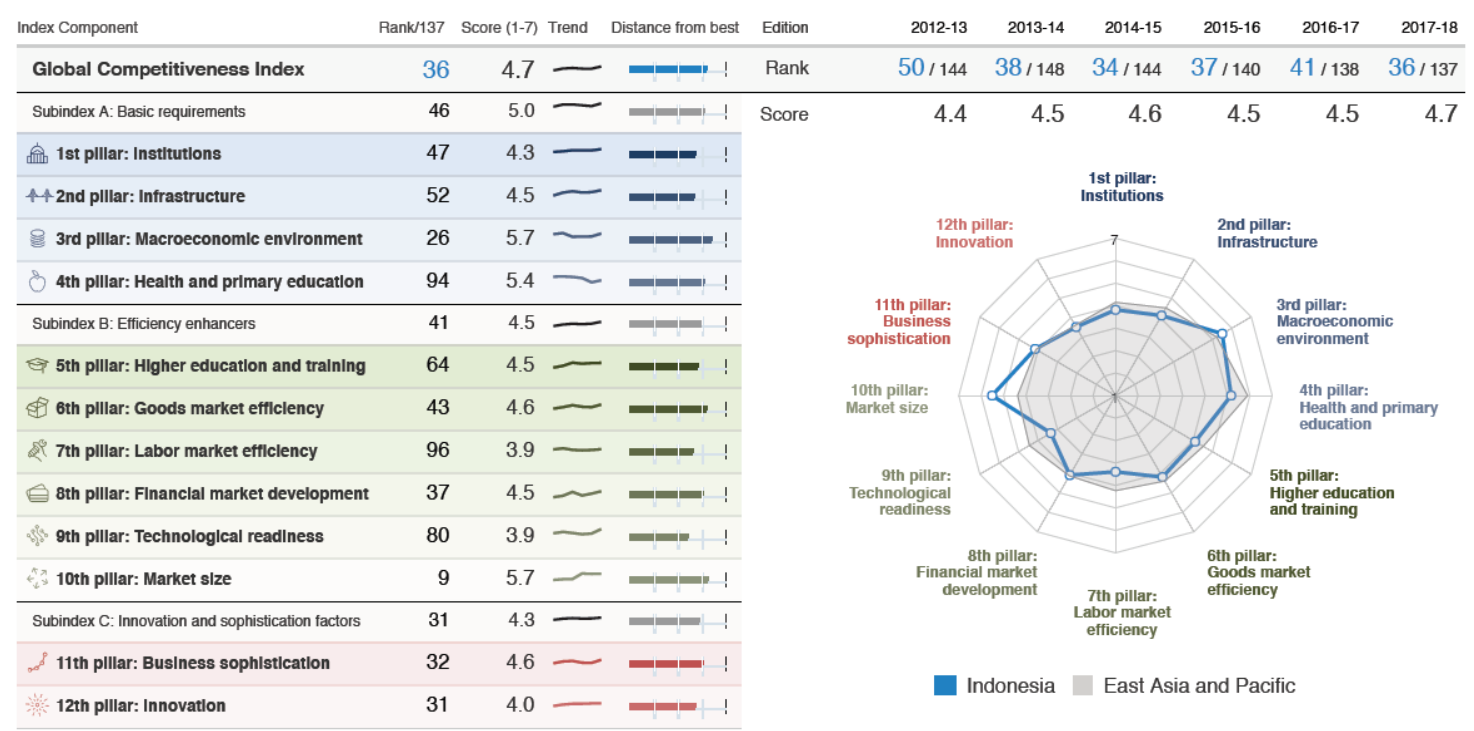

Sumber: Indonesia: The Global Competitiveness Index 2017-2018 edition (2017b)

Ringkasan dari paparan 12 pilar tersebut dikutip dari Indonesia: The Global Competitiveness Index 2017-2018 edition (2017b) dipaparkan sebagai berikut:

Indonesia (36th) is inching its way up the competitiveness ladder, moving ahead five places since last year. Similar to Korea, Indonesia has improved its performance across all of its pillars. Its position in the rankings is driven mainly by its large market size (9th) and a relatively robust macroeconomic environment (26th). Ranking 31 st and 32nd in innovation and business sophistication respectively, Indonesia is one of the top innovators among the emerging economies. In contrast, the country is lagging quite far behind in terms of technological readiness (80th) despite having made steady progress on that front over the last decade. Significant advances are also needed in the labor market efficiency pillar (96th), which is dragged down by excessive redundancy costs, limited flexibility of wage determination, and a limited representation of women in the labor force.

Paparan di atas menunjukkan bahwa ukuran pasar (market size) merupakan peringkat yang merupakan keunggulan Indonesia sedangkan Indonesia justru terperosok di kesiapan teknologi dan efisiensi pasar tenga kerja. Hal ini patut menjadi perhatian pemerintah dan organisasi masyarakat sipil Indonesia, termasuk Persyarikatan Muhammadiyah untuk memperkuat aspek-aspek yang masih lemah bagi Indonesia dalam kompetisi global. 


\section{Persyarikatan Muhammadiyah Merespon Tantangan Dunia Kerja dan Kompetisi Global}

Persyarikatan Muhammadiyah telah memasuki usia yang ke-105 tahun dalam kalender Miladiyah, sedangkan 108 tahun dalam kalender Hijriah pada tahun 2017 lalu. Memasuki abad kedua Persyarikatan Muhammadiyah tentu memiliki tantangan baru yang semakin kompleks dan beragam. Salah satunya merspon tantangan dunia kerja dan kompetisi global. Sebelum membahas lebih jauh mengenai hal tersebut, maka terlebih dahulu tulisan ini merefleksikan perkembangan persyarikatan Muhammadiyah.

Saat ini Persyarikatan Muhammadiyah telah berkembangan sangat luar biasa dalam amal usaha yang dimiliki, diantaranya: Taman Kanak-Kanak/Taman Pendidikan Al-Qur'an mencapai 4.623 unit, Sekolah Dasar (SD)/MI mencapai 2.252 unit, Sekolah Menengah Pertama (SMP)/MTs mencapai 1.111 unit, Sekolah Menengah Atas (SMA)/SMK/MA mencapai 1.291 unit, Pondok Pesantren mencapai 67 unit, Perguruan tinggi Muhammadiyah mencapai 171 unit, Rumah Sakit, Rumah Bersalin, BKIA, BP, dll mecapai 2.119 unit, Panti Asuhan, Santunan, Asuhan Keluarga, dll. mencapai 318 unit, Panti jompo mencapai 54 unit, Rehabilitasi Cacat mencapai 82 unit, Sekolah Luar Biasa (SLB) mencapai 71 unit, Masjid mencapai 6.118 unit, Musholla mencapai 5.080 unit dan Tanah mencapai 20.945.504 $\mathrm{m}^{2}$. (Muhammadiyah.or.id, 2018)

Selain itu, Persyarikatan Muhammadiyah juga telah memiliki unit usaha diantaranya: percetakan, penerbitan, kerajinan, makanan olahan dan sebagainya. Proses ini berlangsung terus sampai hari ini. Kiprah Muhammadiyah di berbagai daerah, relatif memiliki unit usaha ekonomi yang lengkap. Mulai unit usaha yang menggarap permodalan dari yang mikro berupa usaha bersama, koperasi, Baitul Mal (BMT) sampai yang tingkat menengah berupa Bank Perkreditan Syariah, unit usaha produksi juga berkembang, termasuk usaha tani, kerajinan dan industri. Unit usaha perdagangan dan distribusi juga berkembang dari yang bersifat eceran atau retail sampai perdagangan menengah dan besar. (Sutan, 2012:6)

Secara kelembagaan, Persyarikatan Muhammadiyah juga mengembangkan "model praksis gerakan" yang merupakan ikhtiar mempertajam dan mengembangkan usaha (amal usaha, program dan kegiatan) kea rah yang lebih baik, berkualitas, dan berkeunggulan sehingga menjadi model yang dapat direplikasi di seluruh lingkungan Muhammadiyah. Model praksis gerakan dalam bentuk program unggulan atau program yang direvitalisasikan diharapkan mempunyai dampak strategis bagi kemajuan Muhammadiyah. Model praksis gerakan ini dapat meningkatkan keunggulan komparasi dan kompetisi Muhammadiyah secara objektif dan elegan. (Pimpinan Pusat Muhammadiyah, 2015:9-10)

Saat ini Persyarikatan Muhammadiyah makin berkembang dengan usaha dan kegiatan di berbagai bidang seperti lembaga pendidikan, kesehatan, pelayanan sosial, pemberdayaan ekonomi, dan model-model dakwah atau misi gerakan lain yang lebih maju dan diminati masyarakat luas. Banyak hal yang dulu dipelopori Muhammadiyah kini dikembangkan pihak lain yang boleh jadi jauh lebih baik dan kompetitif. Jika 
kecenderungan tersebut tidak diantisipasi dan dihadapi Muhammadiyah dengan usahausaha kreatif, inovatif, dan alternatif yang lebih unggul atau kompetitif maka pelan tapi pasti Muhammadiyah akan ketinggalan dan tidak tertutup kemungkinan ditinggalkan masyarakat. (Pimpinan Pusat Muhammadiyah, 2015:9-10) Oleh karena itu, penulis memberikan dua tawaran sebagai bentuk kontribusi pemikiran kaum muda Muhammadiyah kepada Persyarikatan untuk merespon tantangan dunia kerja dan kompetisi global.

\section{Pendidikan Berbasiskan STEM}

Kompetisi global seperti gelombang yang akan menerjang, tidak ada kompromi, kalau kita tidak siap maka kita akan diterjang, kalau kita tidak mampu maka kita akan menjadi orang tak berguna dan kita hanya akan jadi penonton saja. Akibatnya banyak desakan dari orang tua yang menuntut sekolah menyelenggarakan pendidikan bertaraf internasional dan desakan dari siswa untuk bisa ikut ujian sertifikasi internasional. Sehingga sekolah yang masih konvensional banyak ditinggalkan siswa dan pada akhirnya banyak pula yang gulung tikar alias tutup karena tidak mendapatkan siswa.

Persaingan untuk menciptakan negara yang kuat terutama di bidang ekonomi, sehingga dapat masuk dalam jajaran raksasa ekonomi dunia tentu saja sangat membutuhkan kombinasi antara kemampuan otak yang mumpuni disertai dengan keterampilan daya cipta yang tinggi. Salah satu kuncinya adalah globalisasi pendidikan yang dipadukan dengan kekayaan budaya bangsa Indonesia. Selain itu hendaknya peningkatan kualitas pendidikan hendaknya selaras dengan kondisi masyarakat Indonesia saat ini. Tidak dapat kita mungkiri bahwa masih banyak masyarakat Indonesia yang berada di bawah garis kemiskinan. Dalam hal ini, untuk dapat menikmati pendidikan dengan kualitas yang baik tadi tentu saja memerlukan biaya yang cukup besar. Tentu saja hal ini menjadi salah satu penyebab globalisasi pendidikan belum dirasakan oleh semua kalangan masyarakat.

Adapun Persyarikatan Muhammadiyah melalui perguruan tinggi Muhammadiyah (PTM) sudah memulainya dengan membuat kelas-kelas internasional serta membuat kerjasama internasional dengan perguruan tinggi terkemuka di dunia. UMY, UMS, UMM, dan UAD adalah beberapa contoh PTM yang sudah mengimplementasikannya. Namun dalam upaya menyiapkan sumber daya manusia yang unggul dari sisi pendidikan, tentu tidak hanya berhenti dari 2 hal tersebut. Perlu ada terobosan baru agar alumni-alumni sekolah dan perguruan tinggi Muhammadiyah yang notabenenya adalah kader Persyarikatan mampu bersaing di kancah internasional dan siap menghadapi era kompetisi global.

Salah satu metode yang bisa diimplementasikan oleh Muhammadiyah dalam rangka merespon tantangan dunia dunia kerja dan kompetisi global adalah penggunaan metode STEM dalam proses pembelajaran di sekolah dan perguruan tinggi Muhammadiyah. STEM merupakan singkatan dari sebuah pendekatan pembelajaran interdisiplin antara Science, Technology, Engineering and Mathematics. Torlakson 
dalam Faye Ong dan John McLean (2014) menyatakan bahwa pendekatan dari keempat aspek ini merupakan pasangan yang serasi antara masalah yang terjadi di dunia nyata dan juga pembelajaran berbasis masalah. Pendekatan ini mampu menciptakan sebuah sistem pembelajaran secara kohesif dan pembelajaran aktif karena keempat aspek dibutuhkan secara bersamaan untuk menyelesaikan masalah. Solusi yang diberikan menunjukkan bahwa peserta didik mampu untuk menyatukan konsep abstrak dari setiap aspek.

Pembelajaran dengan menggunakan pendekatan STEM secara langsung memberikan latihan kepada peserta didik untuk dapat mengintegrasikan masing-masing aspek sekaligus. Proses pembelajaran yang melibatkan keempat aspek akan membentuk pengetahuan tentang subjek yang dipelajari lebih dipahami. Bybee (2010) dalah karakter dalam pembelajaran STEM adalah kemampuan peserta didik mengenali sebuah konsep atau pengetahuan dalam sebuah kasus. Sebagaimana dalam pembelajaran fisika, maka STEM membantu peserta didik untuk menggunakan teknologi dan merangkai sebuah sebuah percobaan yang dapat membuktikan sebuah hukum atau konsep sains. Kesimpulan tersebut didukung oleh data yang telah dikelola secara matematis.

Saat ini korporasi-korporasi global merekrut tenaga kerja yang tidak hanya pandai berbahasa asing, tetapi juga punya etos kerja berkualitas dan punya kecerdasan khusus di bidang teknologi informasi. Sejumlah perusahaan lokal-pun mulai pilih-pilih tenaga kerja yang punya kualitas baik. Sehingga sudah seyogyanya Muhammadiyah melalui sekolah-sekolah dan perguruan tingginya mulai menerapkan metode STEM ini agar tercipta kader dan lulusan yang mampu bersaing di era globalisasi saat ini.

\section{Pemberdayaan Masyarakat untuk Menghadapi Era Revolusi Industri 4.0}

Revolusi industri generasi keempat ini ditandai dengan kemunculan super komputer, robot pintar, kendaraan tanpa pengemudi, rekayasa genetik dan perkembangan neuroteknologi yang memungkinkan manusia untuk lebih mengoptimalkan fungsi otak. Revolusi industri 4.0 merupakan integrasi pemanfaatan internet dengan lini produksi di dunia industri. Pembauran ini berdampak pada terciptanya jabatan dan keterampilan kerja baru serta hilangnya beberapa jabatan lama.

Revolusi Industri 4.0 berciri kreativitas, leadership (kepemimpinan) dan entrepreneurship (kewirausahaan) yang mendobrak "mindset" cara bekerja revolusi industri sebelumnya. Dengan berciri efisiensi dalam komunikasi dan transportasi serta mengarahkan masyarakat untuk memecahkan masalah dengan sistem "one stop shopping" atau "one stop solution" diperlukan ekosistem dunia usaha yang lepas dari lilitan dan hambatan birokrasi dan itu tidak hanya soal cara bekerja tapi juga mentalitas pegawai dan tenaga kerjanya. Dan pada gilirannya luaran revolusi ini banyak mendatangkan keuntungan dan kesejahteraan seperti harga barang murah, serta kesehatan terjamin bukan malah menambah beban ekonomi masyarakat dan memperbanyak pengangguran.

Persyarikatan Muhammadiyah sebagai organisasi kemasyarakatan yang sudah lama fokus dalam memberdayakan masyarakat harus mulai mengantisipasi dan 
memetakan kehadiran revolusi industri 4.0 ini. Jika selama ini Muhammadiyah fokus memberdayakan masyarakat melalui Majelis Pemberdayaan Masyarakat (MPM), maka kedepannya Muhammadiyah sekiranya membuat Majelis-Majelis lain yang lebih spesifik dalam menangani strategi pemberdayaan masyarakat yang dikolaborasikan dengan adanya revolusi industri yang saat ini berujung pada lahirnya era disrupsi.

Selama ini pemberdayaan yang dilakukan oleh MPM lebih berfokus pada kaum fakir miskin. Namun dengan adanya era disrupsi saat ini, maka MPM sudah seyogyanya memperluas cakupan kerja pemberdayaannya pada usaha kecil mikro. Karena usaha kecil mikro adalah yang paling terkena dampak dari adanya revolusi industri generasi ke-4 ini.

Muhammadiyah sendiri sebenarnya melalui Pemuda Muhamamdiyah sudah mulai merespon era disrupsi ini dengan menghadirkan semacam toko daring (online) sendiri yang mencoba memfasilitasi saudagar-saudagar Muhammadiyah untuk menjualnya melalui toko daring Pemuda Muhammadiyah tersebut. Ini sebenarnya mirip dengan Tokopedia, Lazada, dan Bukalapak. Namun pengembangan ini sepertinya belum maksimal dan tidak terdengar lagi gaungnya.

Padahal di Muhammadiyah banyak terdapat ahli-ahli pemasaran, IT, hingga konsultan bisnis yang seandainya ini mampu dirangkul dan difasilitasi melalui pendirian start up serta dikolaborasikan dengan MPM, maka ini akan menjadi strategi yang baik untuk ikut memberdayakan masyarakat serta membantu mereka menghadapi era disrupsi.

Selain itu, pergerakan yang terjadi dari Industri 2.0 dan 3.0 menuju industri 4.0 membawa banyak perubahan. Jika sebelumnya revolusi industri bergerak ke lini mechanisation, electrification, hingga automation yang menggunakan elektronik dan IT, kini industri 4.0 bergerak ke arah networking. Pada industri 4.0 ada konektivitas yang lebih besar di bidang manufaktur. Revolusi industri yang terjadi berbasis pada Cyber-Physical Systems yang memungkinkan kemudahan bagi proses produksi tanpa diperlukan dana yang besar. Di era yang disebut sebagai new normal era ini, UKM dan Start-up menjadi pusat pembukaan lapangan kerja (job creation) baru bagi perekonomian.

Dalam upaya mengembangkan dan memberdayakan UKM serta start-up di era industri 4.0 ini, Muhammadiyah perlu membuat master plan untuk meningkatkan global competitiveness masyarakat binaanya, Muhammadiyah dapat membangun benefit sharing schemes meliputi pemberian financing, marketing funding, research and development bagi UKM dan Start-up. Hal ini bisa Muhammadiyah lakukan melalui peningkatan peran PTM pada masyarakat. Selain itu, melalui jaringan Saudagar Muhammadiyah juga mampu membuat kolaborasi pemberdayaan masyarakat ini.

Dari sisi teknologi, core bisnis di industri 4.0 terletak di sisi teknologi. Untuk menghadapi industri 4.0, UKM harus dibekali dengan memperkuat R\&D di bidang teknologi meliputi Cyber Based Tech (Internet of Things, Artificial Intelligence, Big Data, dan Cyber Security), Physical Based Tech (Smart Sensor, Robotics, 3D Printing, 
Augmented Reality/Virtual Reality), dan Platform Technology (5G, Cloud Computing, CPS, HMI UI/UX, Energy system), dimana semua bidang ini sebenarnya dimiliki oleh Muhammadiyah melalui dosen-dosen di perguruan tingginya.

Selain itu, dibutuhkan Humane Entrepreneurship dalam mengembangkan bisnis untuk menghadapi era disrupsi ini. Muhammadiyah perlu melakukan pemberdaayan untuk merubah kultur tradisional masyarakat dalam hal ekonomi untuk menjadi lebih modern.

\section{KESIMPULAN}

Persyarikatan Muhammadiyah di awal berdirinya telah mencapkan pilar kemandirian ekonomi sebagai ciri pergerakan dan perkembangan Muhammadiyah dan ijtihad mendorong kemandirian ekonomi ini juga terus berlanjut dengan mengelola amal usaha dan mendirikan unit usaha. Di samping itu, Muhammadiyah juga turut mengambil bagian di tengah masyarakat global. Hal ini telah sejalan dengan Usaha Muhammadiyah sebagaimana telah ditetapkan dalam Anggaran Rumah Tangga Persyarikatan Muhammadiyah. Seiring semakin maju dan berkembangnya Muhammadiyah, diperlukan tawaran gagasan yang konkrit dan strategis untuk memberdayakan sumber daya manusia Muhammadiyah.

Indonesia dalam 50 tahun terakhir juga mengalami persoalan dalam penyediaan lapangan kerja. Tren yang terlihat pertumbuhan penduduk sejak 1971 tidak sebanding dengan jumlah angkatan kerja dan tenaga kerja yang terserap. Jika ditinjau dari daya saing, Indonesia dalam Global Competitiveness Index (GCI) tahun 2017-2018 menempati posisi 36 dari 137 negara. Keunggulan Indonesia dalam GCI ini hanya pada ukuran pasar (market size) sedangkan kesiapan teknologi dan efisiensi pasar tenaga kerja pada posisi yang memprihatinkan.

Oleh karena itu, dibutuhkan terobosan dari Persyarikatan Muhammadiyah sebagai organisasi masyarakat Islam dan juga bagian dari gerakan masyarakat sipil (civil society) untuk merespon tantangan dunia kerja dan menyokong posisi Indonesia dalam kompetisi global. Hal ini mengingat Muhammadiyah dengan amal usaha dan unit usaha yang semakin berkembang, serta dorongan kelembagaan dengan "model praksis gerakan" yang juga merupakan ikhtiar mempertajam dan mengembangkan usaha ke arah yang lebih baik, berkualitas dan berkeunggulan.

Penulis memberikan dua tawaran konkrit bagi Persyarikatan Muhammadiyah dalam merespon tantangan dunia kerja dan kompetisi global. Pertama, menerapkan pendekatan pembelajaran interdisiplin Science, Technology, Engineering and Mathematics (STEM) melalui sekolah-sekolah dan perguruan tinggi Muhammadiyah agar tercipta kader dan lulusan yang mampu bersaing di era globalisasi. Kedua, pemberdayaan masyarakat yang dilakukan Muhammadiyah berorientasi terhadap Revolusi Industri 4.0 sehingga luaran dari revolusi ini akan mendatangkan keuntungan dan kesejahteraan bagi warga Persyarikatan Muhammadiyah serta rakyat Indonesia secara luas. 


\section{REFERENSI}

Bybee, R. W. (2010). Advancing STEM Education: A 2020 Vision. Technology and Engineering Teacher, 70, 30-35. Diakses dari: https://www.researchgate.net/publication/286200999_Advancing_STEM_education_A_ 2020_vision.

Kementerian Tenaga Kerja dan Transmigrasi/Kemenakertrans. (2011). Perkembangan Ketenagakerjaan di Indonesia. Jakarta: Kemenakertrans. Diakses dari http://www.ilo.org/wcmsp5/groups/public/---asia/---ro-bangkok/---ilojakarta/documents/publication/wcms_157809.pdf.

Muhammadiyah.or.id. Data Amal Usaha Muhammadiyah. Diakses dari http://www.muhammadiyah.or.id/content-8-det-amal-usaha.html pada 31 Maret 2018.

Muhammadiyah.or.id. Tanfidz Keputusan Muktamar Muhammadiyah ke-47. Diakses dari:

http://www.muhammadiyah.or.id/muhfile/download/TANFIDZ\%20MUKTAMAR\%20 47.pdf.

Ong, Faye dan John McLean. (2014). Innovate: A blueprint for science, technology, engineering, and mathematics in california public education, a report to the state superintendent of public instruction. Diakses dari: https://www.cde.ca.gov/pd/ca/sc/documents/innovate.pdf.

Pimpinan Pusat Muhammadiyah. (2015). Tanfidz Keputusan Muktamar Muhammadiyah ke-47. Yogyakarta: Pimpinan Pusat Muhammadiyah. Diakses dari: http://www.muhammadiyah.or.id/muhfile/download/TANFIDZ\%20MUKTAMAR\%20 47.pdf.

Sutan, Fakhrurazi Reno. (2012). Muhammadiyah dan Bisnis. Diakses dari http://tabligh.muhammadiyah.or.id/muhfile/file/artikel/MUHAMMADIYAH\%20DAN $\%$ 20BISNIS.doc.

World Economic Forum. (2017a). The Global Competitiveness Report 2017-2018. Geneva: World Economic Forum. Diakses dari: http://www3.weforum.org/docs/GCR2017-

2018/05FullReport/TheGlobalCompetitivenessReport2017\%E2\%80\%932018.pdf.

World Economic Forum. (2017b). Indonesia: The Global Competitiveness Index 20172018 edition. Geneva: World Economic Forum. Diakses dari: http://reports.weforum.org/pdf/gci-2017-2018/WEF_GCI_2017_2018_Profile_IDN.pdf

Young, J.A. (n.d.) Global Competition-The New Reality. Diakses dari: http://channelingreality.com/Competitiveness/Global_Competition_New_Reality_typed .pdf.

Zulfikar, Achmad. (2015). Mapping the Position of Indonesian Migrant Workers towards ASEAN Economic Community 2015. Makalah. Dipresentasikan pada 1st International Conference of Journal Government and Politics di Universitas Muhammadiyah Yogyakarta, 14 Maret 2015. Diakses dari https://dx.doi.org/10.17605/OSF.IO/5CEFW. 